\title{
VALIDATION OF ASMR2 SEA ICE CONCENTRATION DATA USING MODIS DATA
}

\author{
K. Cho ${ }^{1 *}$, R. Nagao ${ }^{1}$, K. Naoki ${ }^{1}$ \\ ${ }^{1}$ Tokai University, 4-1-1 Kitakaname Hiratsuka, Kanagawa 259-1292, Japan, \\ kohei.cho@tokai-u.jp, 8beim036@mail.u-tokai.ac.jp, naoki@tokai-u.jp
}

Commission III, WG III/9

KEY WORDS: passive microwave radiometer, Bootstrap Algorithm, global warming, GCOM-W

\begin{abstract}
Passive microwave radiometer AMSR2 was launched by JAXA in May 2012 on-board GCOM-W satellite. The antenna diameter of AMSR2 is $2.0 \mathrm{~m}$ which provide highest spatial resolution as a passive microwave radiometer in space. The sea ice concentration images derived from AMSR2 data allow us to monitor the detailed sea ice distributions of whole globe every day. The AMSR bootstrap algorithm developed by Dr. Josefino Comiso is used as the standard algorithm for calculating sea ice concentration from AMSR2 data. Under the contract with JAXA, the authors have been evaluating the performance of the algorithm. The sea ice concentration estimated from AMSR2 data were evaluated using MODIS data observed from Aqua satellite within few minutes after AMSR2 observation from GCOM-W. Since the spatial resolution of MODIS is much higher than that of AMSR2, under the cloud free condition, the ice concentration corresponds to the size of a pixel of AMSR2 can be calculated much accurately with MODIS data. The procedures of the evaluation are as follows. Firstly, MODIS band 1 reflectance were binarized to discriminate sea ice(1) from open water(0) and sea ice concentration of each pixel size of AMSR2 were calculated. In calculating sea ice concentration from MODIS data, the selection of the threshold level of MODIS band 1 reflectance is critical. Through the detailed evaluation, the authors selected $5 \%$ as the optimum threshold level. Then the AMSR2 sea ice concentration of each pixel was compared with the sea ice concentration calculated from MODIS data. The result suggested the possibility of estimating sea ice concentration from AMSR2 data with less than $10 \%$ error under the cloud free condition.
\end{abstract}

\section{INTRODUCTION}

In 1978, the passive microwave radiometer SMMR on-board NIMBUS-7 satellite was launched. Since then, a series of passive microwave radiometers, including AMSR2 onboard GCOM-W satellite, have been continuously observing the earth for over 40 years. Since microwave can penetrate clouds, the global distribution of sea ice can be monitored on daily basis with the passive microwave sensors from space. The long-term sea ice extent derived from the passive microwave observation showed clear decline trend of the Arctic sea ice cover (Comiso, 2012, JAXA, 2012, NSIDC, 2018 etc.). The result is referred as an evidence of global warming in the Fifth Assessment Report of IPCC (2014). Usually, the sea ice concentration derived from passive microwave radiometers are used for calculating sea ice extent. Ice concentration is the most fundamental parameters of sea ice which can be calculated from brightness temperatures measured by passive microwave radiometers. There are number of sea ice concentration algorithms including NASA Team Algorithm (Cavarieli et al., 1984), Bootstrap Algorithm (Comiso, 1995) and ASI Algorithm. As for AMSR2, AMSR Bootstrap Algorithm (Comiso et al., 2013) is used as the standard algorithm for calculating sea ice concentration from ASMR2 data. Under the contract with JAXA, the authors are evaluating the performance of the algorithm. In this study, the authors have evaluated the ways to evaluate AMSR2 sea ice concentration accuracy with MODIS data under the cloudless condition. The result verified the reliability of AMSR2 sea ice concentration data set.

\section{TEST SITE}

In this study, several areas in the Sea of Okhotsk and the Bering Sea from the Northern Hemisphere were selected as test sites. As for the Southern Hemisphere, a part of the Southern Ocean was selected as the test sites. The test sites are shown on Figure 1. Since the Sea of Okhotsk is the southernmost sea ice zone in the Northern Hemisphere, the sun radiation is stronger than the other sea ice zones of the Northern Hemisphere. Thus, the authors have selected the Sea of Okhotsk for the test site to evaluate the threshold level of MODIS band1 reflectance for discriminating sea ice from open water

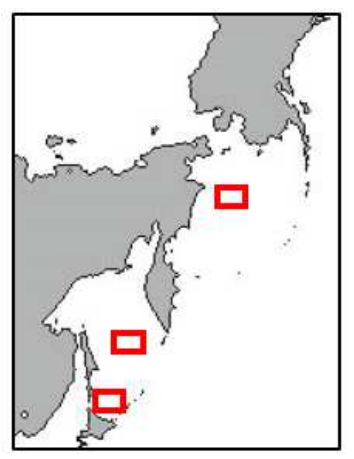

(a)Northern Hemisphere

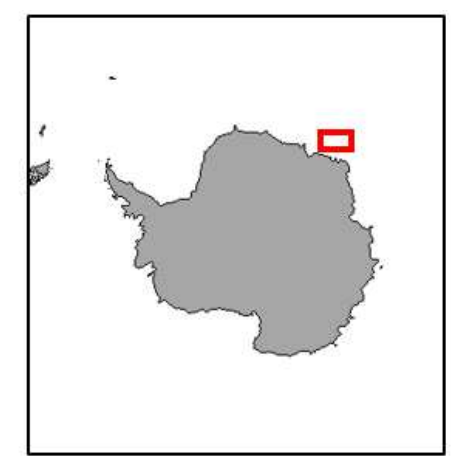

(b) Southern Hemisphere

Figure 1. The location of the test sites

\footnotetext{
*Corresponding author: Kohei Cho, Tokai University

Research \& Information Center, 2-3-23, Takanawa,

Minato-ku, Tokyo, 108-8619, Japan
} 


\section{ANALYZED DATA}

The brightness temperature data acquired from passive microwave radiometer AMSR2 onboard GCOM-W satellite of JAXA were used in this study (JAXA, 2012). Table 1 show the specifications of AMSR2. Also, AMSR2 sea ice concentration data is analysed in this study. The sea ice concentration data is one of the AMSR2 standard product produced by JAXA using AMSR2 Bootstrap Algorithm (Comiso et al., 2009, 2013). In order to verify the sea ice concentration calculated from ASMR2 data, optical sensor MODIS band1 and band2 data were used as reference. Table 2 show the specifications of MODIS Band 1 and Band2. Under the cloud free condition, detailed distribution of sea ice can be observed from MODIS images. Since both Aqua and GCOM-W satellites are in the same orbital under the frame work of the NASA's A-Train (NASA, 2012), the constellation of satellites, MODIS onboard Aqua observed the same area four minutes after the observation of AMSR2 onboard GCOM-W. Therefore, MODIS data is one of the most effective validation data for AMSR2 data. In order to utilize the highest spatial resolution of MODIS, we used only Band 1 and 2 which have $250 \mathrm{~m}$ resolution.

Table 1. Specifications of AMSR2

\begin{tabular}{|c|c|c|c|}
\hline $\begin{array}{c}\text { Frequency } \\
\text { (polarization) }\end{array}$ & IFOV & Swath & $\begin{array}{c}\text { Incident } \\
\text { angle }\end{array}$ \\
\cline { 1 - 2 } $6.925 \mathrm{GHz}(\mathrm{V}, \mathrm{H})$ & $35 \times 62 \mathrm{~km}$ & & \\
\cline { 1 - 2 } $10.65 \mathrm{GHz}(\mathrm{V}, \mathrm{H})$ & $24 \times 42 \mathrm{~km}$ & & \\
\cline { 1 - 2 } $18.7 \mathrm{GHz}(\mathrm{V}, \mathrm{H})$ & $14 \times 22 \mathrm{~km}$ & \multirow{2}{*}{$55 \mathrm{deg}$} \\
\cline { 1 - 2 } $23.8 \mathrm{GHz}(\mathrm{V}, \mathrm{H})$ & $15 \times 26 \mathrm{~km}$ & & \\
\cline { 1 - 2 } $36.5 \mathrm{GHz}(\mathrm{V}, \mathrm{H})$ & $7 \times 12 \mathrm{~km}$ & & \\
\cline { 1 - 2 } $89.0 \mathrm{GHz}(\mathrm{V}, \mathrm{H})$ & $3 \times 5 \mathrm{~km}$ & & \\
\hline
\end{tabular}

Table 2. Specifications of MODIS (NASA, 2012)

\begin{tabular}{|c|c|c|c|}
\hline Band & Wavelength & IFOV & Swath \\
\hline 1 & $0.620-0.670 \mu \mathrm{m}$ & & \\
\hline 2 & $0.841-0.876 \mu \mathrm{m}$ & $250 \mathrm{~m}$ & $2330 \mathrm{~km}$ \\
\hline
\end{tabular}

*The MODIS bands of IFOV $=500 \mathrm{~m}$ and $1 \mathrm{~km}$ are not used in this study.0.841-0.876

\section{SEA ICE CONCETRATION ALGORITHM}

Ice concentration is the most fundamental parameter of sea ice which can be calculated from brightness temperatures measured by passive microwave radiometers. There are number of sea ice concentration algorithms including NASATeam Algorithm (Cavarieli et. al., 1984), Bootstrap Algorithm (Comiso, 1995), and ASI Algorithm (Spreen et al., 2008). JAXA has adopted AMSR2 Bootstrap Algorithm (Comiso et al., 2009) as the standard algorithm for producing AMSR2 ice concentration dataset. Figure 3 shows the schematic diagram of calculating ice concentration (IC) in the AMSR2 Bootstrap Algorithm. In the scatter plot of $36 \mathrm{GHz}$ Vertical polarization (V) vs $18 \mathrm{GHz}$ Horizontal polarization $(\mathrm{H})$, Open water $(\mathrm{IC}=0 \%)$ comes to around point $\mathrm{O}$ and big ice floe $(\mathrm{IC}=100 \%)$ distribute around the line PQ. Let's think that the AMSR2 data of certain sea ice area is plotted on point $S$ in Figure 3. We extent the line OS and find the cross point $\mathrm{F}$ with line $\mathrm{PQ}$. Then, the ice concentration IC of the sea ice area can be calculated with the following equation.

$$
\mathrm{IC}=\mathrm{m} / \mathrm{l}
$$

(1)

Where $\mathrm{m}:$ length of line OS, $1:$ length of line OF

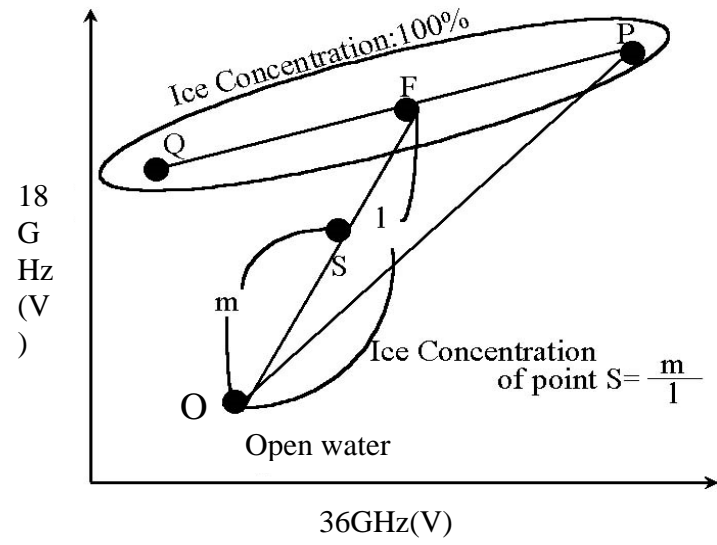

Figure 2. Schematic diagram of calculating ice concentration in the AMSR Bootstrap Algorithm.

\section{METHODOLOGY}

The sea ice concentration estimated from AMSR2 data were evaluated using the data of optical sensor MODIS onboard Aqua satellite. Since the spatial resolution of MODIS band 1 and 2 (IFOV $=250 \mathrm{~m})$ is much higher than the spatial resolution of ice concentration data of AMSR2 (IFOV=approx.. $10 \mathrm{~km}$ to $25 \mathrm{~km}$ ), much detailed sea ice distribution can be observed with MODIS under the cloud free conditions. The procedures of the validation are described on Figure 3. Firstly, MODIS Band 2 data were binarized to discriminate sea ice from open water, and sea ice concentration (the percentage of sea ice in the water) of each pixel size of AMSR2 were calculated using the binarized MODIS data. In this study, the authors have evaluated how the relationship between sea ice concentrations calculated from MODIS and AMSR2 change with the threshold level of MODIS data in the Sea of Okhotsk. Then the AMSR2 sea ice concentration of each pixel was compared with the sea ice concentration calculated from MODIS data.

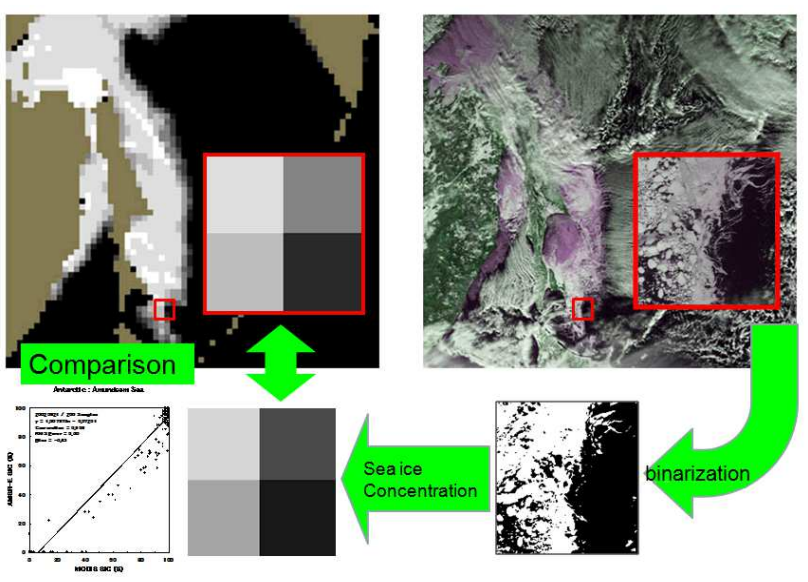

Figure 3. Procedure of validating AMSR2 sea ice concentration using MODIS data 


\section{DIFFICULTY OF BINARIZING MODIS DATA}

Actually, binarizing MODIS image to distinguish sea ice from open water is not easy. The reflectance of one pixel of MODIS is the averaged reflectance of the mixture of sea ice and open water within the area of $250 \mathrm{~m} \times 250 \mathrm{~m}$. If the sea ice concentration of the area is very low or if the area is covered with very thin ice, the reflectance of the area may become nearly as low as open water. Figure 4 show the MODIS image and the FORMOSAT-2/RSI image of a part of the Sea of Okhotsk observed on February 9, 2012. The spatial resolution of MODIS is $250 \mathrm{~m}$, while that of RSI is $2 \mathrm{~m}$. The area A in the MODIS image of Figure 4(a) looks like open water. However, if we see the same area in the RSI image of Figure 4(b), it is clear that the area is mostly covered with thin ice.

Moreover, since one pixel size of AMSR2 is resampled to $25 \mathrm{~km}$ $\mathrm{x} 25 \mathrm{~km}$ in this study, one pixel size of AMSR2 is six times larger than the MODIS image of Figure 4(a). It is not realistic to extract very thin or low concentration sea ice area as sea ice from the MODIS image and evaluate the accuracy of sea ice concentration derived from AMSR2 data. So, in this study, the authors have evaluated the optimal threshold level of binarizing MODIS image to calculate the sea ice concentration for evaluating sea ice concentration derived from AMSR2 data.

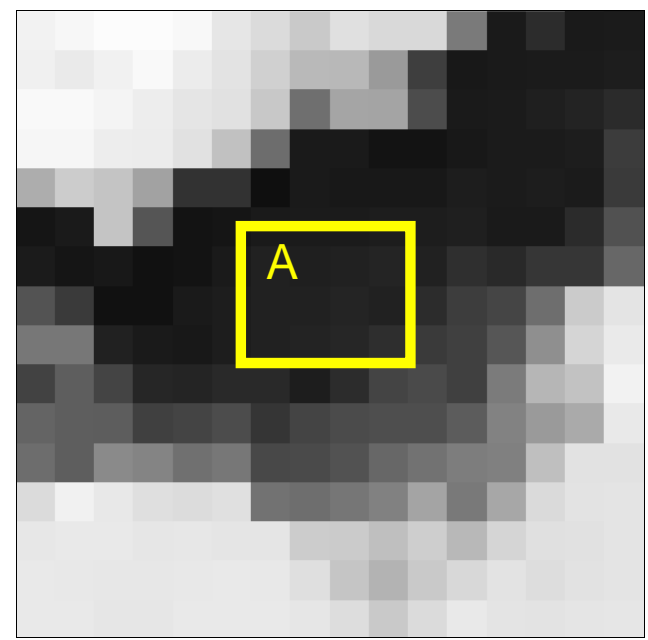

(a)MODIS image (IFOV=250m)

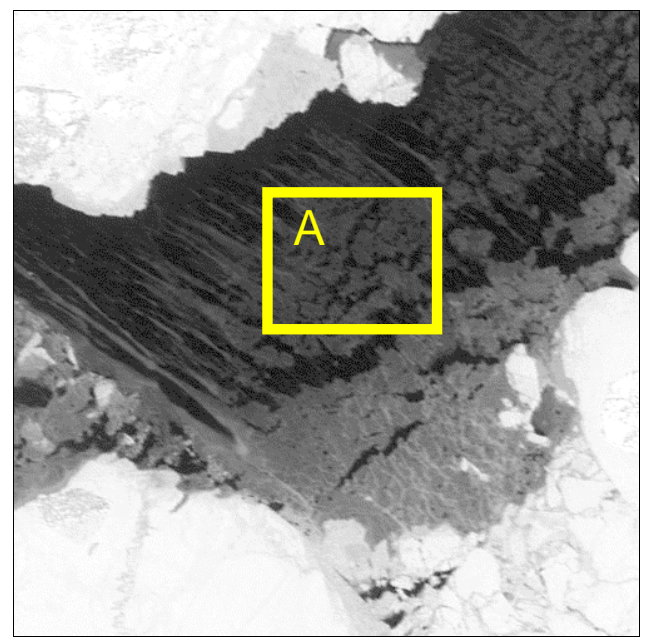

(b)RSI image (IFOV=2m)

Figure 4. Comparison of MODIS image and RSI image (The Sea of Okhotsk, February 9, 2012)
Figure 5 show examples of how the sea ice concentration calculated from MODIS data change as the threshold level of MODIS for binarization change. The reflectance of one pixel of MODIS is the average reflectance of the $250 \mathrm{~m} \times 250 \mathrm{~m}$ area consisted of various types of sea ice and open water. If the threshold level is set to low value, many of the low sea ice concentration area will be assigned to "ice". In this case, the sea ice concentration of one pixel size of AMSR2 will be rather high. On the other hand, if the threshold level is set to high value, many of the low sea ice concentration area will be assigned to "open water". In this case, the sea ice concentration of one pixel size of AMSR2 will be rather low.

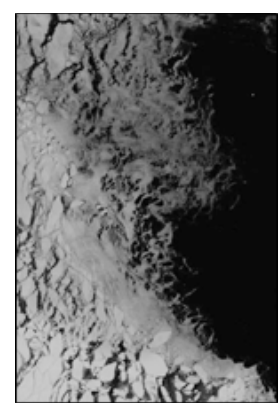

(a)Original MODIS band1

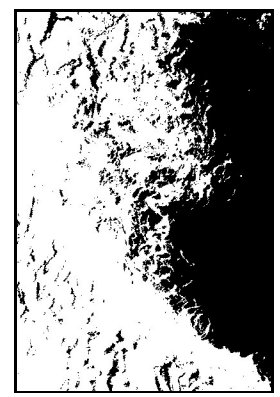

(c)MODIS binarized (L:7\%)

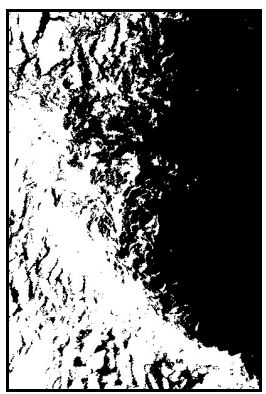

(e) MODIS binarized (L:11\%)

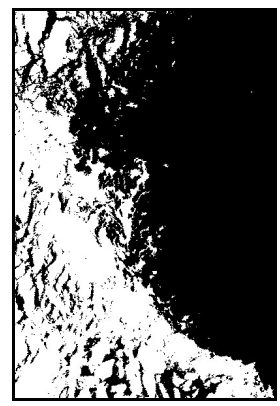

(g) MODIS binarized L:15\%

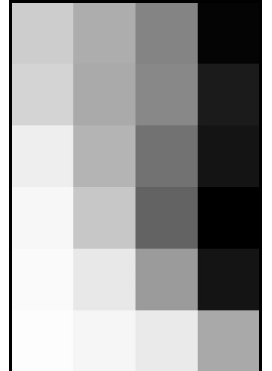

(b) AMSR2 IC

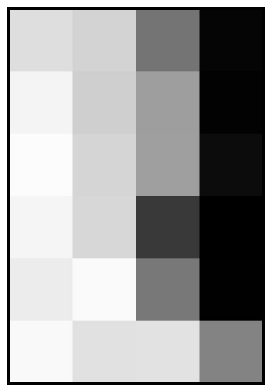

(d) MODIS IC (L:7\%)

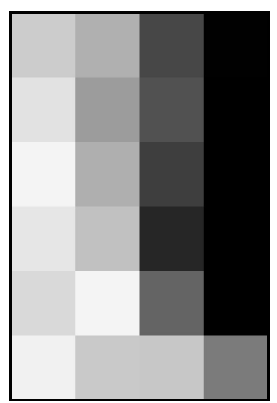

(f)MODIS IC (L:11\%)

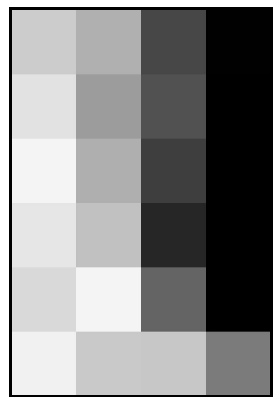

(h)MODIS IC (L:15\%)
Figure 5. Binarization of MODIS data and Ice concentration (IC) image derived from MODIS data. L: Theshold level 


\section{RESULT}

\subsection{Threshold evaluation of MODIS data for binarization}

In order to evaluate how the relationship between sea ice concentrations calculated from MODIS and AMSR2 change with the threshold level of MODIS data, the MODIS and AMSR2 data observed on March 13, 2016 over the Sea of Okhotsk were analysed. Figure 6 show the AMSR2 sea ice concentration(IC) image and MODIS band 1 image of the test site.

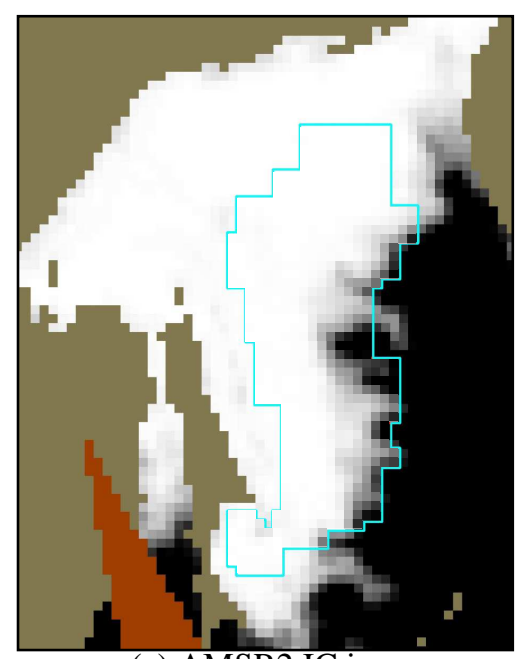

(a) AMSR2 IC image

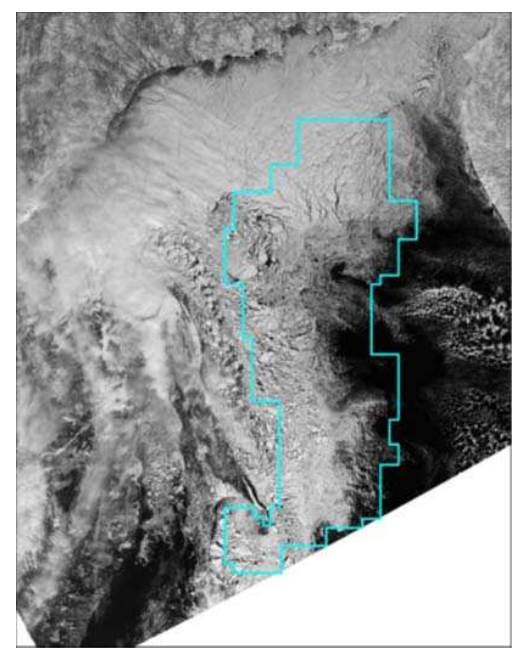

(b) MODIS Band1 image

Figure 6. Test site for evaluating the threshold level of MODIS data for binarization

(Sea of Okhotsk, March 13, 2016)

Firstly, MODIS band1 reflectance data were binarized with the threshold level starting from $2 \%$ to $13 \%$, and the sea ice concentration corresponds to each pixel size of AMSR2 data were calculated. Figure 7 show the relationship between MODIS IC and AMSR2 IC with the changes of threshold level of MODIS band1 reflectance. As the threshold level of MODIS went up, the sea ice concentration derived from MODIS data decreased. Figure 8 show how the RMSE and offset of the graphs change with the setting of the threshold level of MODIS. From this result, the authors have selected 5\% as the threshold level for calculating sea ice concentration from MODIS data.
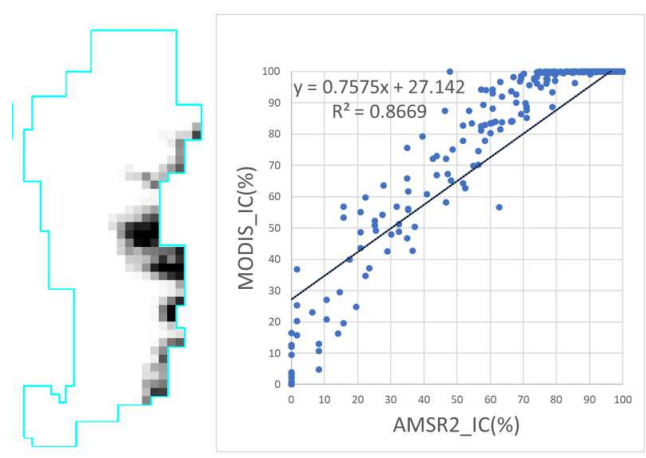

(1)MODIS IC image (2) MODIS IC vs. AMSR2 IC (a) Threshold : 2\%, RMSE: $11.2 \%$

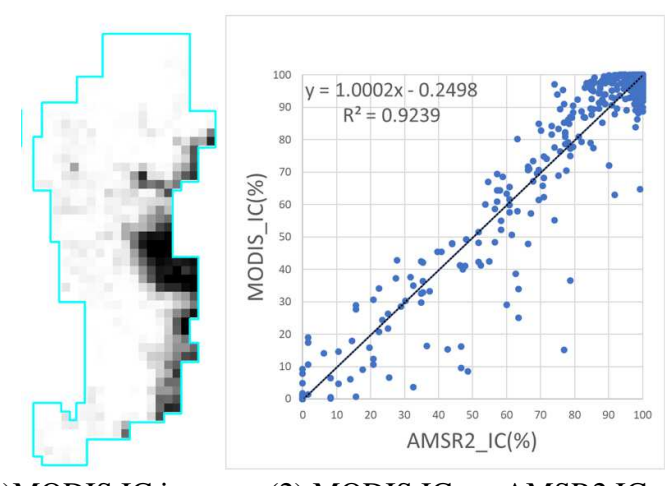

(1)MODIS IC image (2) MODIS IC vs. AMSR2 IC

(b) Threshold : 5\%, RMSE:7.1\%
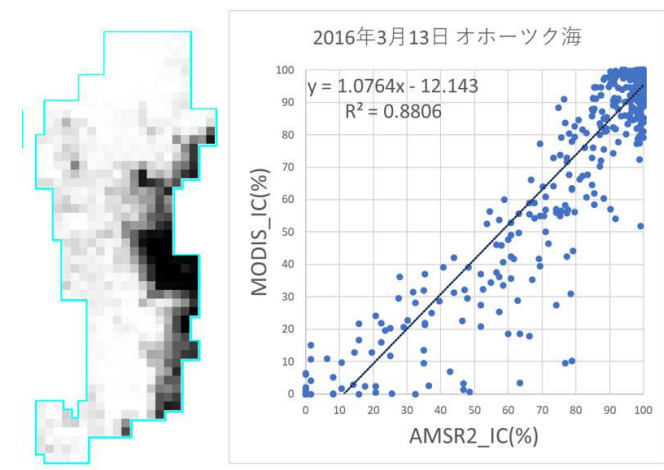

(1)MODIS IC image (2) MODIS IC vs. AMSR2 IC (c) Threshold : 8\%, RMSE: $11.4 \%$
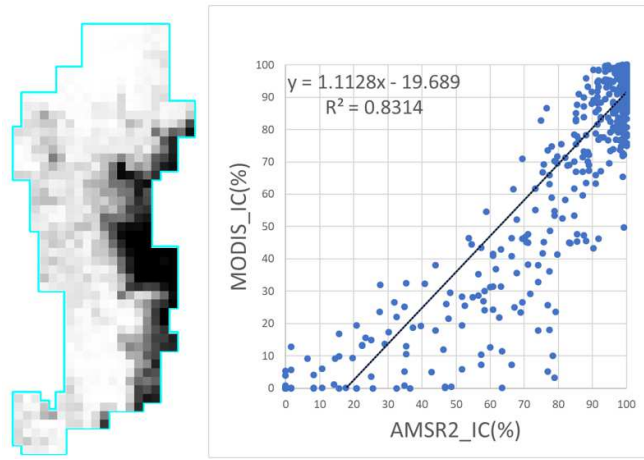

(1)MODIS IC image (2) MODIS IC vs. AMSR2 IC (d) Threshold : 11\%, RMSE: $16.0 \%$

Figure 7. Relationship between MODIS IC and ASMR2 IC with he change of threshold level of MODIS data 


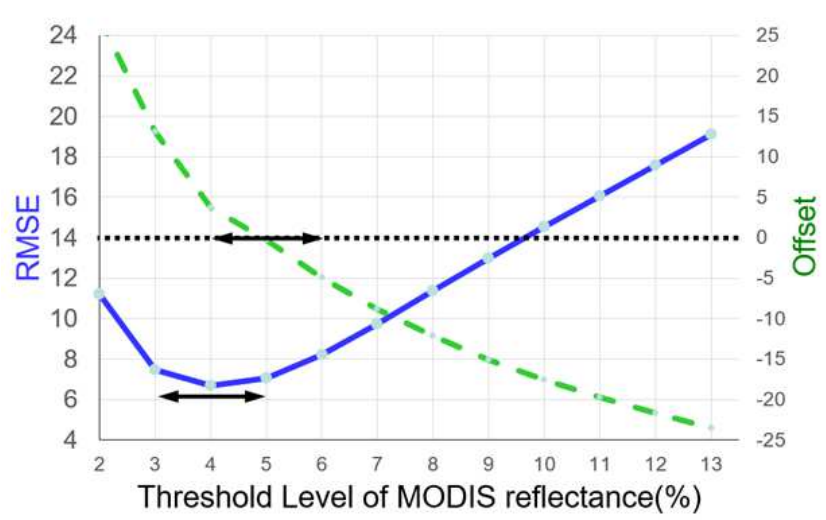

Figure 8. Relationship between threshold level and RMSE\& Offset

\subsection{Evaluation of AMSR2 sea ice concentration data}

The accuracy of AMSR2 sea ice concentration data were evaluated at the test sites in the Sea of Okhotsk, the Bering Sea and the Southern Ocean using the sea ice concentration data derived from MODIS data. The results are shown on Figure 911 and Table 3 .
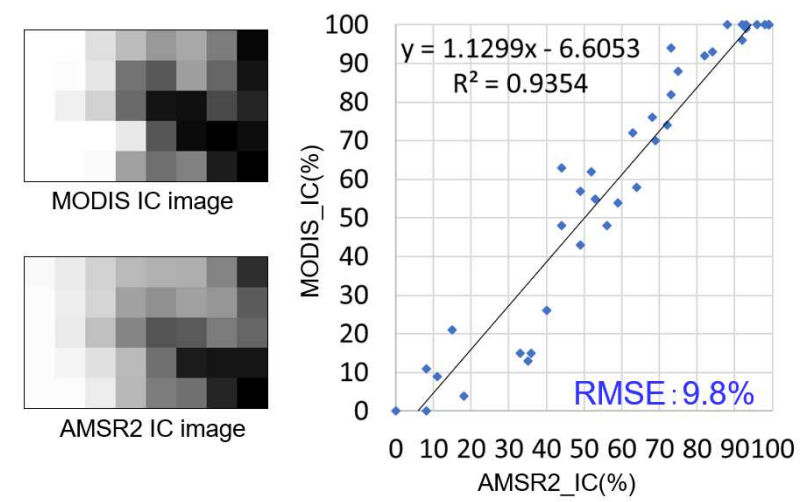

Figure 9. Comparison of MODIS and AMSR2 IC (Sea of Okhotsk, February 24, 2015)
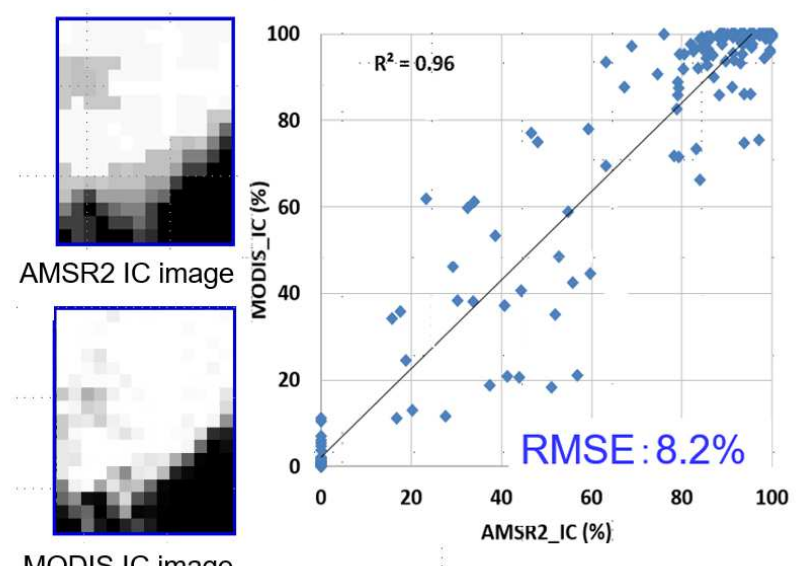

MODIS IC image

Figure 10. Comparison of MODIS and AMSR2 IC (Bering Sea, March 16, 2016)
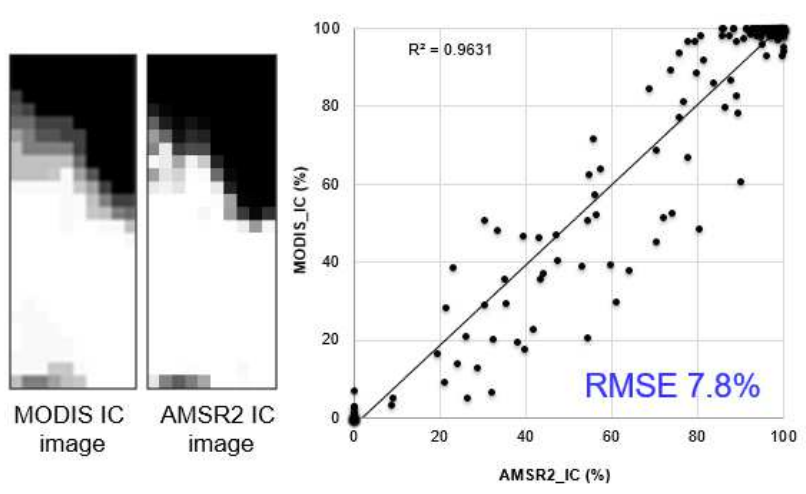

Figure 11. Comparison of MODIS and AMSR2 IC (Southern Sea, December, 11, 2016)

Table 3. Validation result of AMSR2 sea ice concentration

\begin{tabular}{|c|c|c|}
\hline Date & Area & RMSE \\
\hline March 13, 2016 & Sea of Okhotsk & $11.3 \%$ \\
\hline February 4, 2015 & Sea of Okhotsk & $10.1 \%$ \\
\hline March 16, 2016 & Bering Sea & $8.2 \%$ \\
\hline Dec 11, 2016 & Southern Sea & $7.8 \%$ \\
\hline
\end{tabular}

\section{CONCLUSION}

In this study, the authors have evaluated the sea ice concentration estimated from AMSR2 data by using MODIS data observed within few minutes after AMSR2 observation. In calculating sea ice concentration from MODIS data, the MODIS data were binarized to distinguish sea ice from open water. The result suggested that the MODIS reflectance of 5\% was the best threshold level for calculating sea ice concentration from MODIS data to compare AMSR2 sea ice concentration. By using the MODIS sea ice concentration as truth data, the RMSE of the AMSR2 ice concentration were $7.8 \%$ to $11.3 \%$. This result suggested that under the certain conditions, the $\mathrm{RMSE}=10 \%$ can be acquired with AMSR 2 ice concentration. However, some more studies are needed to identify the optimal threshold level to binarize MODIS data for calculating sea ice concentration.

\section{ACKNOWLEDGEMENTS}

This study was supported by JAXA under the framework of GCOM-W Project. The authors would like to thank JAXA for their kind support.

\section{REFERENCES}

JAXA, 2012, http://suzaku.eorc.jaxa.jp/GCOM_W/w_amsr2/ whats_amsr2_j.html.

Comiso, J. C., 2009, Enhanced Sea Ice Concentrations and Ice Extent from AMSR-E Data, Journal of the Remote Sensing Society of Japan, Vol.29, No.1, pp.199-215.

Comiso, J. C., K. Cho, 2013, Description of GCOM-W1 AMSR2 Sea Ice Concentration Algorithm, Descriptions of 
GCOM-W1 AMSR2 Level 1R and Level 2 Algorithms, JAXA, NDX-120015A, (6)1-28, Available online:

http://suzaku.eorc.jaxa.jp/GCOM_W/data/doc/NDX-120015A.pdf

NASA, 2012, Afternoon Constellation, http://atrain.nasa.gov/

NASA, 2015, http://modis.gsfc.nasa.gov/about/specifications.php

Cavalieri, D. J. and P. Gloersen, 1984, Determination of sea ice parameters with the NIMBUS 7 SMMR, J. Geophys. Res., Vol.89, pp.5355-5369.

Comiso, J. C., 1995, SSM/I Sea Ice Concentrations Using the Bootstrap Algorithm", NASA Reference Publication 1380, Maryland, NASA Center for AeroSpace Information.

Spreen G., L. Kaleschke, and G. Heygster, 2008, Sea ice remote sensing using AMSR-E $89 \mathrm{GHz}$ channels, J. Geophys. Res., Vol. 113, C02S03, doi:10.1029/2005JC003384.

Revised April 2019 